\title{
Ketamine for Adults with Severe Asthma Exacerbation: A Systematic Review and Meta-analysis
}

\author{
Fatimah AlShehri, Heetaf Aloqaily, Joud Enabi, and Sharafaldeen Bin Nafisah
}

\begin{abstract}
BACKGROUND: Severe asthma mandates careful attention and timely management, and the benefit of ketamine in severe asthma exacerbations in adult patients require further exploration.

METHODS: We conducted a systematic review and meta-analysis of the use of ketamine in cases of acute asthma exacerbation in adults. We searched PubMed, Google Scholar, Cochrane databases, and gray literature (ClinicalTrials.gov and World Health Organization International Clinical Trials Registry Platform); we also searched the reference lists of included articles and any systematic reviews and meta-analyses identified therein. Our search covered the period from 1963 to August 20, 2021. Search terms were "ketamine" AND "asthma".
\end{abstract}

RESULTS: Of 25540 articles, two studies were included in the analysis. The total number of patients included in the studies was 136 (68 in the ketamine groups and 68 in the placebo group). The pooled effect size was $0.30(95 \%$ CI: $-0.04,0.63)$ favouring ketamine over placebo, $\mathrm{p}=0.08,\left(\mathrm{I}^{2}=0 \%, \mathrm{p}=0.39\right)$. A paired t-test revealed that ketamine improved the mean peak expiratory flow rate (PEFR) from 242.4 ( $\mathrm{SD}=146.23)$ to $286.95(\mathrm{SD}=182.22), \mathrm{p}=\mathbf{0 . 3 3}$, representing an $18.38 \%$ improvement.

CONCLUSION: Ketamine can induce a $30 \%$ improvement in PEFR, representing a small positive effect in the treatment of acute severe asthma exacerbation in the emergency department (ED). The improvement was not statistically significant; nonetheless, since the improvement could be as great as $63 \%$

Fatimah AlShehri, Heetaf Aloqaily, Sharafaldeen Bin Nafisah are with Emergency Department, King Fahd Medical City, e-mail: fatmaalshehri26@gmail.com, e-mail: Heetaf.Aloqaily@gmail.com, e-mail:

Dr.Sharafaldeen@yahoo.com (Corresponding author: Fatimah AlShehri)

Joud Enabi is with Alfaisal University, e-mail: Jenabi@alfaisal.edu versus only a $4 \%$ possibility of no benefit/harm, the benefit appears to considerably outweigh any harm.

Index Terms-Ketamine and asthma, severe asthma, asthma exacerbation

\section{INTRODUCTION}

Severe asthma exacerbation is an everyday encounter in the ED. Once the patient has reached a severe stage, it is often a life-threatening condition in which response to therapy is variable with a propensity to disease morbidity and mortality $[1,2]$. Although most cases respond promptly to various therapies, some patients deteriorate rapidly, making timely and appropriate management crucial to their survival. To this end, several attempts have been made to classify patients based on their current clinical condition, response to initial management, and previous history of exacerbations.

It is now a standard of care to manage severe exacerbations using nebulised salbutamol, ipratropium and corticosteroids, with some role for theophylline, leukotriene receptor antagonists and epinephrine $[3,4]$. In addition, ketamine has gained attention for improving outcomes and mitigating the need for mechanical ventilation [5]. However, the use of ketamine in severe asthma requires additional evidentiary exploration.

The first report of ketamine used for asthma was probably in the late 1970s [6]. In various experimental studies, ketamine was found to have a bronchodilatory effect by relaxing the smooth muscles of the airway and suppressing various inflammatory cascades. This was believed to be via its inhibitory effect on the vagal system [7]. However, it is now accepted that ketamine's primary mechanism of action is bronchodilation through the activation of 
adrenaline receptors, hampering histamine-induced bronchoconstriction [8]. Nevertheless, emergence phenomena and the high profile of side effects and contraindications might have delayed its use as a standard of care in patients with severe exacerbations. Therefore, ketamine for asthma is given in a sub-dissociative dose, resulting in more negligible side effects, particularly the emergence phenomena [9].

Several attempts have been made to explore the evidence behind the use of ketamine in asthma. A well-known meta-analysis was conducted of severe exacerbations, but did not demonstrate a measurable benefit [10]. However, this was outdated and was conducted among paediatric patients. No other meta-analysis was found at the time of this writing, particularly among adult patients with severe exacerbation. Randomised controlled trials are available, but with conflicting results. Our aim in this systematic review is to investigate the effect of ketamine on the peak expiratory flow rate (PEFR) test in adult patients with severe asthma exacerbation.

\section{METHODS}

Review question: Is ketamine effective in treating severe acute asthma exacerbations in adult patients?

Study design: We conducted a systematic review and meta-analysis on the use of ketamine in cases of acute asthma exacerbation in adults.

Types of studies included: Randomised controlled trials.

Study population: Non-intubated adult patients with severe acute asthma exacerbations.

Search Strategy: We searched PubMed, Google Scholar, Cochrane databases, and gray literature (ClinicalTrials.gov and World Health Organization International Clinical Trials Registry Platform); we also searched the reference lists of included articles and any systematic reviews and meta-analyses identified therein. Our search covered the period from 1963 to August 20, 2021. The search was limited to published articles in the English language, or nonEnglish articles which had been scientifically translated into English. We searched for meta-analyses and systematic reviews on the use of ketamine for asthma exacerbations in adults. Search terms were "ketamine" AND "asthma".
Data Extraction and Management: We screened titles and abstracts, looked for published articles, and extracted data for the analysis of this systematic review. Data retrieved included the studies' time frames, populations, and outcomes. We excluded non-English studies, studies conducted on paediatric age groups, prehospital studies, and studies conducted on animals. The article adhered to the reporting guidelines of the Preferred Reporting Items for a Review and Meta-analysis of Individual Participant Data [11].

Data Synthesis and Summary Measures: In our systematic review, we focused on including studies that used ketamine as a bronchodilator in severe asthma exacerbations in adults.

Data Analysis: We performed a meta-analysis of the included studies. On the assumption that the effect size may vary among the included studies, we used a random analysis. We also conducted a funnel plot to examine for possible publication bias. Sensitivity analyses were omitted, given the low number of included studies. We used a paired t- test to measure PEFR before and after the use of ketamine.

\section{FUNDING RESOURCE:}

No funds, grants, or support were received.

\section{CONFLICT OF INTEREST:}

The authors declare no conflict of interest.

\section{APPROVAL:}

This study was approved by the IRB board, with log number 21-417.

\section{RESULTS}

Of 25540 articles, two studies were included in this analysis. The Prisma chart is illustrated in Figure 1. There was a total of 136 patients in the included studies (68 in the ketamine groups and 68 in the placebo group). The patients' demographic details are illustrated in Table 1. The quality of the included studies was assessed for the risk of bias using the RoB 2 tool [12], illustrated in Table 2. 


\section{Identification of studies via databases and registers}

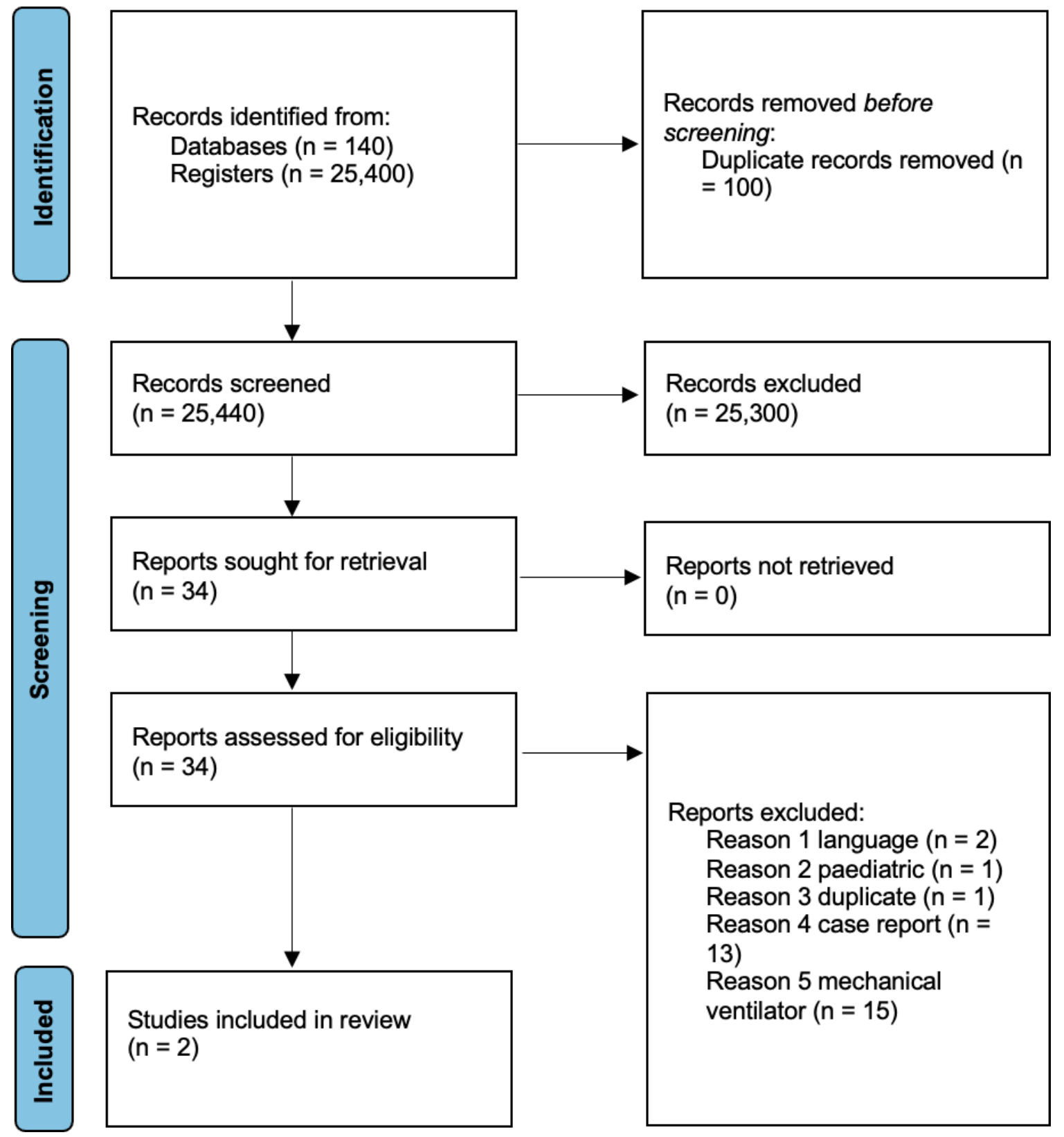

Fig. 1. Prisma chart of included studies

\section{TABLE I}

Demographic details of patients in the included studies 


\begin{tabular}{|c|c|c|}
\hline & Esmailian et al. (2018) & Howton et al. (1994) \\
\hline Age & $\begin{array}{l}48.5 \text { years }(\mathrm{SD}=13.95) \text {; ranging from } 18 \\
\text { to } 85 \text { years }\end{array}$ & $\begin{array}{l}33.9 \text { years }(S D=8.24) \text {; ranging from } 18 \text { to } 65 \\
\text { years }\end{array}$ \\
\hline \multirow[t]{2}{*}{ Gender } & Male $40.2 \%(n=37)$ & Male $65.95 \%(n=31)$ \\
\hline & Female $59.8 \%(\mathrm{n}=55)$ & Female $34.05 \%(n=16)$ \\
\hline Severity & $\begin{array}{l}\text { PEFR of less than } 70 \% \text { (moderate to } \\
\text { severe) upon presentation }\end{array}$ & $\begin{array}{l}\text { Only PEFR of less than } 40 \% \text { (severe) after } \\
\text { initial management }\end{array}$ \\
\hline Ketamine dose & $\begin{array}{l}0.3,0.4 \text {, or } 0.5 \mathrm{mg} / \mathrm{kg} \text { IV over } 1-2 \\
\text { minutes, then infusion of the same dose } \\
\text { over } 30 \text { minutes }\end{array}$ & $\begin{array}{l}0.2 \mathrm{mg} / \mathrm{kg} \text { over } 5 \text { minutes, then infusion of } \\
0.5 \mathrm{mg} / \mathrm{kg} \text { per hour for } 3 \text { hours. After the } 9 \text { th } \\
\text { patient, the bolus dose was reduced to } 0.1 \\
\mathrm{mg} / \mathrm{kg} \text { over } 5 \text { minutes, while the infusion } \\
\text { remained the same. }\end{array}$ \\
\hline PEFR measurement & $\begin{array}{l}\text { Before and } 1 \text { hour after ketamine } \\
\text { administration }\end{array}$ & $\begin{array}{l}\text { Before and } 3 \text { hours after ketamine } \\
\text { administration }\end{array}$ \\
\hline Exclusion criteria & $\begin{array}{l}\text { The existence of any "prohibition for } \\
\text { using IV ketamine", and history of allergy } \\
\text { to the medication. }\end{array}$ & $\begin{array}{l}\text { History of COPD, need for intubation, } \\
\text { hypertension, coronary artery disease, } \\
\text { hyperthyroidism, pregnancy, psychiatric } \\
\text { disorders, inability to perform spirometry or } \\
\text { allergy to the medication. }\end{array}$ \\
\hline
\end{tabular}

PEFR: Peak expiratory flow rate; COPD: Chronic obstructive pulmonary disease

TABLE II

ROB 2 tools to assess risk of bias in the included studies

\begin{tabular}{|c|c|c|c|c|c|c|c|}
\hline Inclusion & $\begin{array}{c}\text { Sequence } \\
\text { generation }\end{array}$ & $\begin{array}{c}\text { Allocation } \\
\text { concealment }\end{array}$ & $\begin{array}{c}\text { Blinding of } \\
\text { participants and } \\
\text { trial personnel }\end{array}$ & $\begin{array}{l}\text { Blinding of } \\
\text { outcome } \\
\text { assessor }\end{array}$ & $\begin{array}{l}\text { Incomplete } \\
\text { outcome } \\
\text { data }\end{array}$ & $\begin{array}{c}\text { Selective } \\
\text { outcome } \\
\text { reporting }\end{array}$ & $\begin{array}{l}\text { Other } \\
\text { sources } \\
\text { of bias }\end{array}$ \\
\hline $\begin{array}{l}\text { Howton } \\
\text { et al., } \\
1996\end{array}$ & + & + & + & + & + & - & $?$ \\
\hline $\begin{array}{l}\text { Esmailian } \\
\text { et al., } \\
2018\end{array}$ & + & + & + & + & + & - & $?$ \\
\hline
\end{tabular}

The pooled effect size (standardised mean difference between ketamine vs placebo group means) from a random-effects model was 0.30 (95\% confidence interval: $-0.04,0.63)$ using Cohen's d, favouring ketamine over placebo. However, the p-value exceeded the arbitrary level of $5 \%$ to $8 \%(p=0.08)$. The forest plot is illustrated in Figure 2. There was no evidence of heterogeneity $\left(\mathrm{I}^{2}=0 \%\right.$; Cochrane's $\mathrm{Q}=0.74 ; \mathrm{p}=0.39$ ). The funnel plot was symmetrical, making publication bias less likely, as illustrated in Figure 3. We investigated the effect of ketamine on the improvement (or deterioration) in PEFR using a paired t-test, and noted that ketamine improved mean PEFR from 242.4 ( $\mathrm{SD}=146.23)$ to 286.95 $(\mathrm{SD}=182.22), \mathrm{p}=0.33$, representing an $18.38 \%$ improvement. Likewise, using normal saline as a placebo, PEFR improved from 230.1 ( $\mathrm{SD}=150.04$ ) to $257.6(\mathrm{SD}=133.64), \mathrm{p}=0.25$, representing an
$11.95 \%$ improvement.

\section{DISCUSSION}

Ketamine can induce a $30 \%$ improvement in PEFR, representing a small positive effect in the treatment of acute severe asthma exacerbation in the ED. This improvement was not statistically significant; nonetheless, since the improvement could be as great as $63 \%$ versus only a $4 \%$ possibility of no benefit/harm, the benefit appears to considerably outweigh any harm. Moreover, the percentage change in PEFR revealed a $42.40 \%$ improvement compared with placebo, using a t-test. This further supports the superiority of ketamine for such patients. However, further studies are needed to ascertain whether the benevolent effect on PEFR is related solely to ketamine, or results from the delayed synergistic effect of salbutamol and 


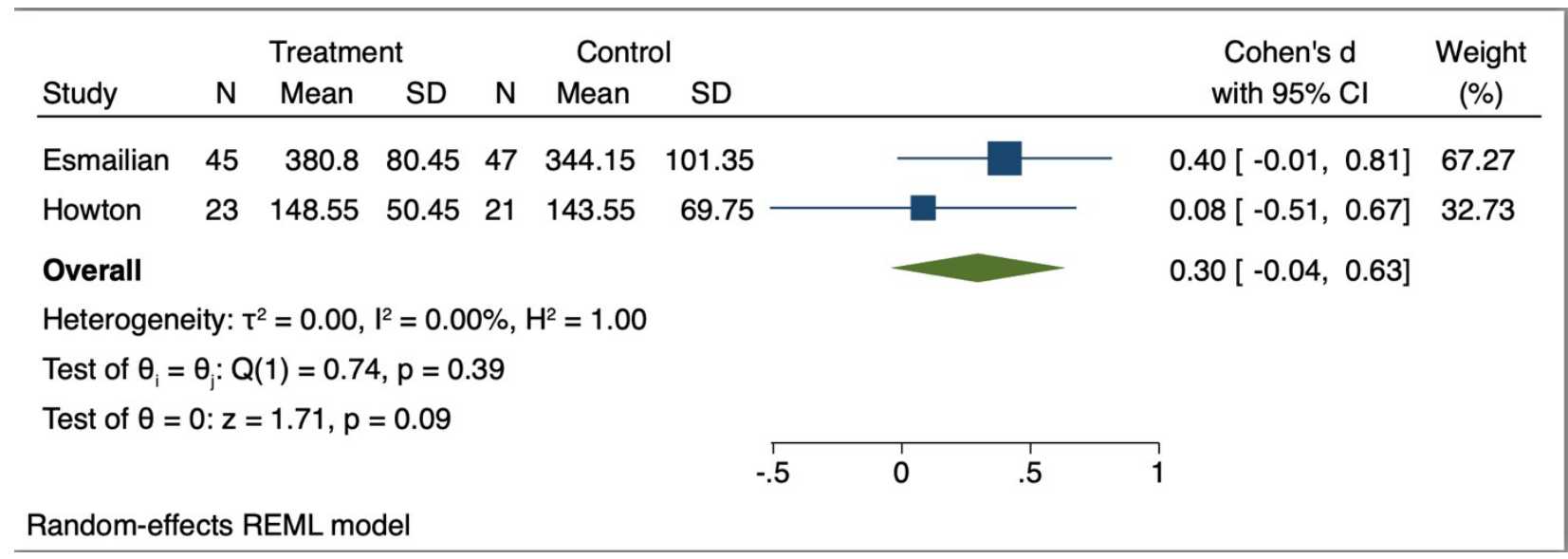

Fig. 2. Forest plot illustrating the effect of ketamine on peak expiratory flow rate

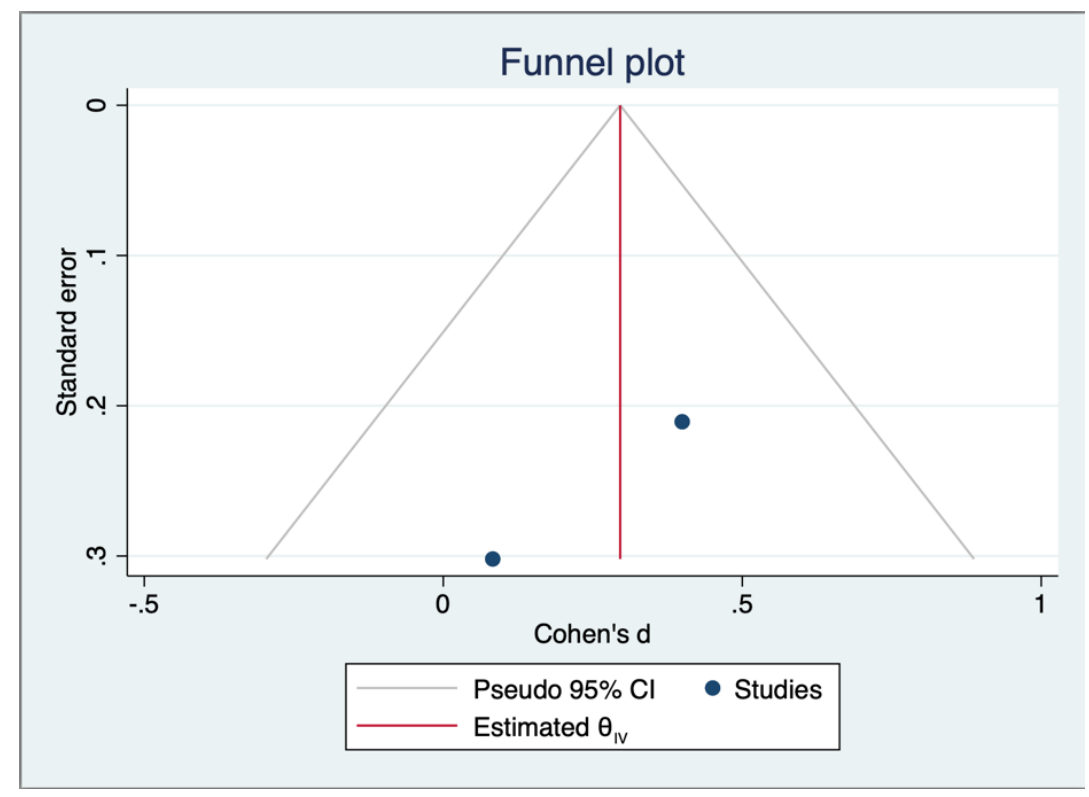

Fig. 3. Funnel plot of included studies

ipratropium [13] and/or the delayed effect of steroid [14].

Ketamine appears to be an ideal drug for moderate to severe asthma exacerbations, given the weak evidence behind administering epinephrine for asthma patients and ketamine's association with improvement in patients with hidden anaphylaxis $[15,16]$. In addition, the mortality and morbidity associated with intubating such patients might favour the use of every other method available before intubation $[17,18]$. The use of such drugs should be protocolised, and patients must be monitored for the development of any side effects. The side effects of ketamine that affect the respiratory system, including apnoea, laryngospasms, secretions and respiratory depression, may be detrimental for non-monitored patients, especially those with exacerbations triggered by upper respiratory tract infection [19-21]. However, the latter is observed in paediatrics, and further studies are required in adults before making a recommendation against its use.

The number of studies included in this analysis is a weakness that might be overlooked, especially when there is no risk of publication bias, low risk of bias in the included articles, and improvement is observed using two methods of statistical analysis. However, further analysis, that unifies several outcome measures using mean change, for instance, is required to properly assess the influence ofketamine on patients with severe exacerbations. Furthermore, 
the reverse physiology of intubated patients and the multiple medications used beyond acute management precluded our inclusion of such patients. It is probable that the inclusion of those patients, as well as pediatric patients, would provide a more comprehensive overview of ketamine for this illness.

\section{CONCLUSION}

This article uncovered a benevolent effect of ketamine $(0.1-0.5 \mathrm{mg} / \mathrm{kg}$ over $1-5$ minutes boluses, followed by $0.3-0.5 \mathrm{mg} / \mathrm{kg} /$ hour infusion) in patients with moderate to severe asthma exacerbations in the ED, and it is our belief that the benefit might outweigh the risk. However, close monitoring of such patients is imperative for the early detection and management of any possible adverse events.

\section{REFERENCES}

[1] Bai TR, Vonk JM, Postma DS, Boezen HM. Severe exacerbations predict excess lung function decline in asthma. Eur Respir J. 2007 Sep;30(3):4526. doi: 10.1183/09031936.00165106. Epub 2007 May 30. PMID: 17537763.

[2] Hodder R, Lougheed MD, Rowe BH, FitzGerald JM, Kaplan AG, McIvor RA. Management of acute asthma in adults in the emergency department: nonventilatory management. CMAJ. 2010 Feb 9;182(2):E55-67. doi: 10.1503/cmaj.080072. Epub 2009 October 26. PMID: 19858243; PMCID: PMC2817338.

[3] Lommatzsch M, Virchow JC. Severe asthma: definition, diagnosis and treatment. Dtsch Arztebl Int. 2014 Dec 12;111(50):847-55. doi: 10.3238/arztebl.2014.0847. PMID: 25585581; PMCID: PMC4357024.

[4] Zervas E, Samitas K, Papaioannou AI, Bakakos P, Loukides S, Gaga M. An algorithmic approach for the treatment of severe uncontrolled asthma. ERJ Open Res. 2018 March 6;4(1):001252017. doi: 10.1183/23120541.00125-2017. PMID: 29531957 ; PMCID: PMC5838355.

[5] Goyal S, Agrawal A. Ketamine in status asthmaticus: A review. Indian J Crit Care Med. 2013 May;17(3):154-61. doi: 10.4103/09725229.117048. PMID: 24082612; PMCID: PMC3777369.

[6] Hirshman CA, Downes H, Farbood A, Bergman NA. Ketamine block of bronchospasm in experimental canine asthma, Br J Anaesth 1979; 51: 713-8,

[7] Wilson LE, Hatch DJ, Rehder K. Mechanisms of the relaxant action of ketamine on iso- lated porcine trachealis muscle. Br J Anaesth. 1993 Oct;71(4):544-50. doi: 10.1093/bja/71.4.544. PMID: 8260305 .

[8] Hirota K, Sato T, Rabito SF, Zsigmond EK, Matsuki A. Relaxant effect of ketamine and its isomers on histamine-induced contraction of tracheal smooth muscle. Br J Anaesth. 1996 Feb;76(2):26670. doi: 10.1093/bja/76.2.266. PMID: 8777108 .

[9] Motov S, Drapkin J, Likourezos A, Doros J, Monfort R, Marshall J. Sub-dissociative dose ketamine administration for managing pain in the emergency department. World J Emerg Med. 2018;9(4):249-255. doi: 10.5847/wjem.j.19208642.2018.04.002. PMID: 30181791; PMCID: PMC6117536.

[10] Jat KR, Chawla D. Ketamine for management of acute exacerbations of asthma in children. Cochrane Database Syst Rev. 2012 Nov 14;11(11):CD009293. doi: 10.1002/14651858.CD009293.pub2. PMID: 23152273 ; PMCID: PMC6483733.

[11] Page MJ et al. The PRISMA 2020 Statement: An Updated Guideline for Reporting Systematic Reviews. BMJ, 2021, p. n71. Crossref, doi:10.1136/bmj.n71.

[12] Methods.cochrane.org. 2021. RoB 2: A revised Cochrane risk-of-bias tool for randomized trials. [online] Available at:

$<$ https://methods.cochrane.org/bias/resources/rob2-revised-cochrane-risk-bias-tool-randomized-trials $>$ [Accessed 25 September 2021].

[13] Lanes SF, Garrett JE, Wentworth CE 3rd, Fitzgerald JM, Karpel JP. The effect of adding ipratropium bromide to salbutamol in the treat- ment of acute asthma: a pooled analysis of three trials. Chest. 1998 Aug;114(2):365-72. doi: 10.1378/chest.114.2.365. PMID: 9726716.

[14] Klaustermeyer WB, Choi SH. A perspective on systemic corticosteroid therapy in severe bronchial asthma in adults. Allergy Asthma Proc. $2016 \quad$ May;37(3):192-8. doi: 10.2500/aap.2016.37.3941. PMID: 27178888.

[15] Rees HA, Millar JS, Donald KW. Adrenaline in bronchial asthma. Lancet. 1967 
Dec 2;2(7527):1164-7. doi: 10.1016/s01406736(67)91889-2. PMID: 4168376.

[16] Cydulka R, Davison R, Grammer L, Parker $\mathrm{M}$, Mathews $\mathrm{J}$ 4th. The use of epinephrine in the treatment of older adult asthmatics. Ann Emerg Med. 1988 Apr;17(4):322-6. doi: 10.1016/s01960644(88)80772-8. PMID: 3354935.

[17] Kao CC, Jain S, Guntupalli KK, Bandi V. Mechanical ventilation for asthma: a 10-year experience. J Asthma. 2008 Sep;45(7):552-6. doi: 10.1080/02770900801999090. PMID: 18773325.

[18] D'Amato G, Vitale C, Molino A, Stanziola A, Sanduzzi A, Vatrella A, Mormile M, Lanza M, Calabrese G, Antonicelli L, D’Amato M. Asthmarelated deaths. Multidiscip Respir Med. 2016 Oct 12;11:37. doi: 10.1186/s40248-016-0073-0. PMID: 27752310; PMCID: PMC5059970.

[19] Rosenbaum SB, Gupta V, Palacios JL. Ketamine. [Updated $2021 \mathrm{Feb}$ 19]. In: StatPearls [Internet]. Treasure Island (FL): StatPearls Publishing; 2021 Jan-. Available from: https://www.ncbi.nlm.ni h.gov/books/NBK470357/

[20] Gao M, Rejaei D, Liu H. Ketamine use in current clinical practice. Acta Pharmacol Sin. 2016 Jul;37(7):865-72. doi: 10.1038/aps.2016.5. Epub 2016 March 28. PMID: 27018176; PMCID: PMC4933765.

[21] Dolansky G, Shah A, Mosdossy G, RiederM. What is the evidence for the safety and efficacy of using ketamine in children? Paediatr Child Health. 2008 Apr;13(4):307-8. doi: 10.1093/pch/13.4.307. PMID: 19337601; PMCID: PMC2529431. 